IP B

\title{
Grupos funcionais em áreas com histórico de queimadas em Cerrado sentido restrito no Distrito Federal
}

\author{
Mary Naves da Silva Rios ${ }^{1 *}$, José Carlos Sousa-Silva² \\ 1 Universidade de Brasília, Campus Universitário Darcy Ribeiro, CEP 70910-900, Brasília, DF, Brasil \\ ${ }^{2}$ Embrapa Cerrados, BR 020, Km 18, CP 08223, CEP 73310-970, Planaltina, DF, Brasil
}

*Autor correspondente:
mnavesrios@hotmail.com

Termos para indexação:

Diversidade funcional

Rebrota

Reabilitação florestal

Index terms:

Functional diversity

Sprouting

Forest rehabilitation

Recebido em 22/11/2016

Aprovado em 10/09/2017

Publicado em 29/09/2017

doi: 10.4336/2017.pfb.37.91.1386

\begin{abstract}
Resumo - O estudo teve como objetivo avaliar a formação de grupos funcionais em duas áreas de Cerrado sentido restrito com diferentes históricos de fogo, em Planaltina, DF, em 1994 e em 2012. Na Área 1, foram aplicadas queimadas bienais, em agosto de 1988, 1990 e 1992; na Área 2, houve proteção do fogo até julho de 1994. Em agosto de 1994 um fogo acidental atingiu as duas áreas, mas de setembro de 1994 até 2012 estas áreas foram protegidas. Nas análises, foram incluídos os indivíduos com abundância $\geq$ 5 utilizando-se o método de agrupamento de ligação média não ponderada (UPGMA). Os grupos foram definidos de acordo com os atributos: síndromes de dispersão e de polinização, fenologia foliar, forma de vida, tipo de casca e capacidade de rebrotar após queimadas. Houve diferenças na formação dos grupos funcionais nas duas áreas e nas duas épocas. A maior frequência de queimadas bienais, na Área 1 em 1994, reuniu espécies funcionalmente semelhantes, com menor diversidade de atributos. A exclusão do fogo favoreceu a entrada de espécies e a maior diversidade de atributos funcionais em 2012.
\end{abstract}

\section{Functional groups in areas with fire history in a savanna area in Brazilian Federal District}

\begin{abstract}
This study aimed to evaluate the formation of functional groups, in 1994 and 2012, in two areas of savanna with different fire history in Planaltina, Federal District, Brazil. In the Area 1 biennial burnings were applied in August 1988, 1990 and 1992; there was fire protection until July 1994 in the Area 2, the control area. Accidental fire occurred in both areas in August 1994, but from September 1994 to 2012 they were protected. These analysis included individuals with abundance $\geq 5$ using the unweighted pair group method with arithmetic mean (UPGMA). The groups were defined according to the following attributes: dispersal and pollination syndromes, leaf phenology, life form, type of bark and ability to sprouting after fire. Both areas presented differences in the formation of functional groups in 1994 and 2012. Species functionally similar and with lower diversity of attributes were observed in Area 1, in 1994. The exclusion of fire favored the recruitment of other species and greater diversity of functional attributes in 2012.
\end{abstract}

\section{Introdução}

A abordagem funcional auxilia na compreensão do funcionamento e manutenção dos processos ecológicos das comunidades (Petchey \& Gaston, 2006; Deng et al., 2008; Cianciaruso et al., 2009). Comunidades com alta diversidade funcional devem operar de forma mais eficiente, indicando que uma maior amplitude de 
recursos está sendo mais bem utilizada (Tilman, 2001; Sobral \& Cianciaruso, 2012). A diversidade funcional categórica, medida pelo número de grupos funcionais de uma comunidade, é considerada a medida mais antiga e mais comum de diversidade (Cianciaruso et al., 2009).

Grupos funcionais podem ser definidos como o conjunto de espécies que apresentam semelhanças em termos de atributos (Muller et al., 2007; Cianciaruso et al., 2009), relacionados às respostas a determinadas condições ambientais ou aos efeitos em processos do ecossistema (Muller et al., 2007). As alterações nos grupos funcionais, geralmente, estão relacionadas às variações em certas condições ambientais, como solo, clima, intensidade e frequência de distúrbios (Muller et al., 2007).

Em áreas queimadas frequentemente, o fogo pode agir como um filtro ambiental e selecionar espécies com capacidade de sobreviver e tolerar as condições abióticas derivadas deste distúrbio (Cianciaruso et al., 2009; Silva et al., 2011). O fogo pode reunir espécies com características funcionais semelhantes (Silva \& Batalha, 2010; Cianciaruso et al., 2012) e eliminar espécies com pouca ou nenhuma adaptação a este distúrbio (Medeiros \& Miranda, 2005; Silva et al., 2011; Zilli et al., 2014). Assim, as queimadas frequentes podem reduzir a diversidade funcional de comunidades do Cerrado (Cianciaruso et al., 2010; Silva et al., 2011).

Diversos atributos podem ser utilizados na busca de grupos funcionais (Vale et al., 2011). As síndromes de polinização e dispersão, por exemplo, estão ligadas à habilidade de recolonização diante de distúrbios (Cianciaruso et al., 2012; Pérez-Harguindeguy et al., 2013), e a forma de vida pode estar associada ao vigor competitivo e à resposta aos distúrbios (Cornelissen et al., 2003; Zilli et al., 2014). Por outro lado, a espessura e o tipo de casca são fundamentais para conferir resistência ao fogo (Heringer \& Jacques, 2001), pois a casca protege o câmbio, xilema e floema das altas temperaturas durante queimadas (Cornelissen et al., 2003; Silva et al., 2011).

A fenologia vegetativa de espécies do Cerrado tem sido relacionada às estratégias para evitar os danos provocados pela seca (Lenza \& Klink, 2006; Souza et al., 2015). E, de forma geral, as plantas decíduas evitam a seca pela produção de folhas pouco longevas e apresentam taxas insignificantes de transpiração no período seco; espécies sempre-verdes toleram a seca com elevada longevidade foliar e fluxo transpiracional por todo o ano (Souza et al., 2015). No entanto, a ocorrência de fogo também pode alterar o período de produção de folhas destas espécies, tanto das decíduas quanto das sempre-verdes (Lenza \& Klink, 2006; Lucena et al., 2015; Silvério et al., 2015).

A reprodução assexuada, característica de várias plantas do Cerrado, tem sido mencionada como um atributo de resistência ao fogo (Miranda \& Sato, 2005; Sartorelli et al., 2007; Salazar \& Goldstein, 2014). E a habilidade para rebrotar após o fogo tem sido associada ao vigor competitivo e à persistência após distúrbios ambientais (Cornelissen et al., 2003; Cianciaruso et al., 2012; Silva et al., 2013), como queimadas e corte de árvores (Cornelissen et al., 2003). Em espécies lenhosas, a rebrota após a ocorrência de fogo pode ocorrer em órgãos aéreos, na base do caule e em estruturas subterrâneas (Coutinho, 1990; Sartorelli et al., 2007).

Nesse trabalho fez-se a análise da formação de grupos funcionais em duas áreas com diferentes históricos de fogo (Área 1, Área 2), e em duas épocas, 1994 e 2012, e procurou-se responder à seguinte questão: A incidência de queimadas modifica os atributos de grupos funcionais de plantas lenhosas?

\section{Material e métodos}

\section{Área de estudo}

O estudo foi conduzido em um fragmento de Cerrado sentido restrito na Reserva Cerrado da Embrapa Cerrados, Nordeste do Distrito Federal, na região administrativa de Planaltina, DF, nas coordenadas $15^{\circ} 38^{\prime}$ 'S e $47^{\circ} 43^{\prime} \mathrm{W}$, datum horizontal Córrego Alegre, MG (Parron et al., 1998). O solo é do tipo Latossolo Vermelho (Santos et al., 2013), textura muito argilosa, relevo plano a suave ondulado, fase cerrado (Typic haplustox), desenvolvido a partir da decomposição da cobertura detrítico-laterítica de caráter argiloso do Terciário. O clima é caracterizado como Aw na classificação de Köppen, com uma estação seca de 5 meses, precipitação média anual de $1.577 \mathrm{~mm}$, temperatura média anual de $20,4{ }^{\circ} \mathrm{C}$, temperatura máxima média de $26,6^{\circ} \mathrm{C}$, e mínima média de $15,8^{\circ} \mathrm{C}$, com altitude de $1.100 \mathrm{~m}$ (Spera et al., 2000).

\section{Amostragem e coleta dos dados}

O trabalho foi desenvolvido em duas áreas de cerca de 1,25 ha, com diferentes históricos de fogo, sendo: Área 1, com aplicação de queimadas bienais controladas em agosto de 1988, de 1990 e de 1992, fogo acidental em 
agosto de 1994, e proteção contra o fogo de setembro de 1994 até 2012; Área 2, protegida contra o fogo de 1988 a julho de 1994, e de setembro de 1994 até 2012, e com fogo acidental em agosto de 1994.

A amostragem da vegetação teve início em 1988, quando, em cada área, foram demarcadas duas transecções de $100 \mathrm{~m}$ de comprimento e $10 \mathrm{~m}$ de largura, e distanciadas $10 \mathrm{~m}$ entre si. Neste ano foram instaladas parcelas de $20 \mathrm{~m}$ x $10 \mathrm{~m}$. No entanto, em 1990 foram alocadas unidades amostrais de $10 \mathrm{~m} \times 10 \mathrm{~m}\left(100 \mathrm{~m}^{2}\right)$ ao longo das mesmas transecções, totalizando 20 parcelas e 0,2 ha em cada área. Nos levantamentos, foram incluídas as espécies arbóreo-arbustivas que atingiam o critério de inclusão de um metro ou mais de altura (MuellerDombois \& Ellemberg, 1974). Até 1994, o levantamento dos dados ocorreu nos meses de junho-julho, antes das queimadas, e em 2012, em setembro.

As coletas de material botânico fértil foram depositadas no Herbário da Universidade de Brasília (UB), Herbário do Jardim Botânico de Brasília - Ezechias Paulo Heringer (HEPH), Herbário da Reserva Ecológica do IBGE e da Embrapa Recursos Genéticos e Biotecnologia - CENARGEN (CEN), em Brasília, Distrito Federal.

\section{Análise dos dados}

A formação de grupos funcionais foi avaliada em 1994 e em 2012, de acordo com alguns atributos relacionados ao distúrbio pelo fogo, tanto na Área 1 quanto na Área 2. Foram incluídas as espécies que tiveram abundância maior ou igual a 5 indivíduos nos levantamentos florísticos de 1994 e de 2012. Esse critério foi baseado em outros trabalhos que sugerem que as espécies com número reduzido de indivíduos apresentam pouca ou nenhuma influência sobre os resultados (Araújo et al., 2010).

Os grupos foram definidos de acordo com os seguintes atributos funcionais: síndrome de dispersão (anemocórica, autocórica ou barocórica, zoocórica), síndrome de polinização (anemófila, zoófila), fenologia foliar (decídua, sempre-verde), forma de vida (arbusto, árvore), tipo de casca (liso, não liso) e capacidade de rebrotar após fogo (sim, não).

Quanto à síndrome de dispersão, as espécies foram classificadas em: anemocóricas - sementes ou frutos apresentam mecanismos que facilitam a dispersão pelo vento; autocóricas ou barocóricas - dispersam sementes ou frutos por gravidade ou apresentam mecanismos de auto-dispersão, como a deiscência explosiva; zoocóricas
- diásporos com características relacionadas à dispersão por animais (Pijl, 1982). Quanto à polinização, as espécies foram classificadas em anemófilas e zoófilas. $\mathrm{Na}$ anemofilia foram incluídas plantas polinizadas pelo vento; na zoofilia foram incluídas plantas polinizadas por insetos (abelhas, moscas, mariposas, borboletas e outros pequenos insetos), morcegos e pássaros (Bawa, 1990).

Com relação à deciduidade, as plantas decíduas são aquelas que perdem as folhas na estação seca, mas também foram incluídas as espécies brevidecíduas, pois perdem suas folhas em um período curto de tempo. As espécies classificadas como sempre-verdes são aquelas que retêm as folhas durante o todo ano, incluindo as semidecíduas, pois não perdem todas as folhas ao longo do ano (Vale et al., 2013). A casca foi classificada de acordo com o aspecto da camada mais externa, sendo considerada casca lisa aquela com superfície sem cicatrizes foliares, deiscências, fendas, fissuras, lenticelas ou rugosidades, e não lisa (ou de aspecto áspero), aquela onde a superfície apresenta cicatrizes foliares, deiscências, fendas, fissuras, lenticelas ou rugosidades irregulares, sem um padrão ou de forma desorganizada (Silva Junior, 2005).

Com relação às formas de vida, as espécies foram classificadas em árvore ou arbusto.

As espécies lenhosas podem responder de diferentes formas aos danos causados pelo fogo. Como consequência do dano moderado ou topkill, que é a morte da parte aérea, pode haver rebrotamento na parte basal do tronco ou em órgãos subterrâneos (Medeiros \& Miranda, 2008; Moreira et al., 2009; Sato et al., 2010). A capacidade de formação de rebrotas foi avaliada nas duas áreas durante o período de 1988 a 1994, classificando como espécies capazes aquelas que rebrotaram, da base do caule ou de estruturas subterrâneas, após dano moderado ou topkill com as queimadas bienais e na ausência do fogo. $\mathrm{Na}$ Área 1, após a incidência da terceira queimada, as rebrotas subterrâneas ou da parte basal das plantas foram formadas de 1993 até 1994, após a morte da parte aérea (topkill). Na Área 2 também houve desenvolvimento de rebrotas.

Desta forma, os atributos foram avaliados de acordo com os dados obtidos na literatura (dispersão, polinização, deciduidade, forma de vida, tipo de casca) e em observações de campo (capacidade de rebrotar, forma de vida e tipo de casca). Os grupos funcionais foram analisados por meio de técnicas de agrupamento, seguindo a metodologia usada por Vale et al. (2011). 
Foram feitas matrizes de presença/ausência, de acordo com os atributos qualitativos de cada espécie. Foi calculado o índice de similaridade de Jaccard entre as espécies e com esses coeficientes foi construído um dendrograma usando-se o método de agrupamento de ligação média não ponderada (UPGMA) (Valentin, 2000). O coeficiente de correlação cofenética foi utilizado como medida de concordância entre os agrupamentos obtidos e a matriz de distância original (Valentin, 2000; Vale et al., 2011). Foi usado o programa FITOPAC (Shepherd, 2010) para a análise dos dados.

\section{Resultados}

Nas análises de formação de grupos funcionais foram avaliadas 52 espécies, que variaram em cada ano. Em 1994 foram 384 indivíduos distribuídos em 32 espécies, na Área 1, com três queimadas bienais, e 852 indivíduos, em 34 espécies, na Área 2. Em 2012, com 18 anos de proteção contra o fogo, foram registrados 1.231 indivíduos, distribuídos em 47 espécies na Área 1, e 1.152 indivíduos, em 37 espécies na Área 2. Os atributos funcionais, definidos de acordo com observações de campo e com consultas bibliográficas, variaram e podem ser observados na Tabela 1.

Tabela 1. Lista de espécies arbóreo-arbustivas utilizadas nas análises de formação de grupos funcionais em dois anos do monitoramento $(1994,2012)$ em duas áreas (Área 1, Área 2) de Cerrado sentido restrito, com respectivos atributos de classificação, em Planaltina, DF.

\begin{tabular}{|c|c|c|c|c|c|c|c|c|}
\hline Espécie & $\begin{array}{c}\text { Nome } \\
\text { abreviado }\end{array}$ & Casca & REB & FV & POL & DIS & FL & Fontes \\
\hline Aegiphila verticillata Vell. & AEGVERT & A & $\operatorname{sim}$ & $\mathrm{AV}$ & zoo & zooc & $\mathrm{D}$ & 20 \\
\hline Annona crassiflora Mart. & ANNCR & A & não & AV & zoo & $\begin{array}{l}\text { auto } \\
\text { zooc }\end{array}$ & $\mathrm{D}$ & $11,17,23$ \\
\hline Annona monticola Mart. & ANNMO & $\mathrm{L}$ & $\operatorname{sim}$ & $\mathrm{AB}$ & zoo & zooc & $\mathrm{D}$ & $4,5,6,14$ \\
\hline Annona tomentosa R.E.Fr. & ANNTO & $\mathrm{L}$ & não & $\mathrm{AB}$ & zoo & zooc & $\mathrm{D}$ & $4,5,6,14$ \\
\hline Aspidosperma macrocarpum Mart. & ASPIMA & A & $\operatorname{sim}$ & AV & zoo & anem & $\mathrm{D}$ & $11,13,17,23$ \\
\hline Aspidosperma tomentosum Mart. & ASPITO & A & $\operatorname{sim}$ & $\mathrm{AV}$ & zoo & anem & $\mathrm{D}$ & $11,17,23,19$ \\
\hline Bauhinia dumosa Benth. & BAUDU & $\mathrm{L}$ & não & $\mathrm{AB}$ & zoo & auto & $\mathrm{D}$ & $1,6,13$ \\
\hline Byrsonima coccolobifolia Kunth & BYRCO & A & não & AV & zoo & zooc & $\mathrm{D}$ & $7,8,13,17,23$ \\
\hline Byrsonima verbascifolia $(\mathrm{L}$.$) DC.$ & BYRVE & A & não & AV & zoo & zooc & $\mathrm{D}$ & $7,11,13,17,23$ \\
\hline Caryocar brasiliense Cambess. & CARYBR & A & $\operatorname{sim}$ & AV & zoo & zooc & $\mathrm{D}$ & $7,11,17,19,23$ \\
\hline Chomelia ribesioides Benth. ex A.Gray & CHOMRI & A & não & $\mathrm{AB}$ & zoo & zooc & $\mathrm{D}$ & $7,10,11$ \\
\hline Connarus suberosus Planch. & CONNSU & A & $\operatorname{sim}$ & AV & zoo & zooc & $\mathrm{D}$ & $11,17,23$ \\
\hline Cordiera sessilis (Vell.) Kuntze & CORDSE & A & não & $\mathrm{AB}$ & zoo & zooc & SV & $2,7,9$ \\
\hline Dalbergia miscolobium Benth. & DALBMI & A & $\operatorname{sim}$ & AV & zoo & anem & $\mathrm{D}$ & $2,11,19,23$ \\
\hline Dimorphandra mollis Benth. & DIMOMO & A & $\operatorname{sim}$ & AV & zoo & zooc & $\mathrm{D}$ & $11,17,23$ \\
\hline Diospyros burchellii Hiern & DIOSBUR & A & não & AV & zoo & zooc & $\mathrm{D}$ & 7,23 \\
\hline $\begin{array}{l}\text { Eremanthus goyazensis (Gardner) Sch. } \\
\text { Bip. }\end{array}$ & EREMGOY & A & não & $\mathrm{AB}$ & zoo & anem & SV & $12,17,18,25$ \\
\hline $\begin{array}{l}\text { Eriotheca pubescens (Mart. \& Zucc.) } \\
\text { Schott \& Endl. }\end{array}$ & ERIOPU & A & não & AV & zoo & anem & $\mathrm{D}$ & $19,22,23,25$ \\
\hline Erythroxylum deciduum A.St.-Hil. & ERYTDE & A & $\operatorname{sim}$ & AV & zoo & zooc & $\mathrm{D}$ & $1,10,23$ \\
\hline Erythroxylum suberosum A.St.-Hil. & ERYTSU & A & $\operatorname{sim}$ & AV & zoo & zooc & $\mathrm{D}$ & $7,11,17,23$ \\
\hline $\begin{array}{l}\text { Guapira graciliflora (Mart. ex Schmidt) } \\
\text { Lundell }\end{array}$ & GUAPGR & $\mathrm{L}$ & $\operatorname{sim}$ & AV & zoo & zooc & $\mathrm{D}$ & 7,23 \\
\hline Guapira noxia (Netto) Lundell & GUAPNO & A & $\operatorname{sim}$ & AV & zoo & zooc & $\mathrm{D}$ & $11,19,23$ \\
\hline $\begin{array}{l}\text { Handroanthus ochraceus (Cham.) } \\
\text { Mattos }\end{array}$ & HANDOC & A & $\operatorname{sim}$ & AV & zoo & anem & $\mathrm{D}$ & $11,17,21,23$ \\
\hline Heteropterys byrsonimifolia A.Juss. & HETEBY & A & não & AV & zoo & anem & $\mathrm{D}$ & $1,13,23$ \\
\hline
\end{tabular}


Tabela 1. continuação

\begin{tabular}{|c|c|c|c|c|c|c|c|c|}
\hline Espécie & $\begin{array}{c}\text { Nome } \\
\text { abreviado }\end{array}$ & Casca & REB & FV & POL & DIS & FL & Fonte \\
\hline Hymenaea stigonocarpa Mart. ex Hayne & HYMEST & A & $\operatorname{sim}$ & AV & zoo & zooc & $\mathrm{D}$ & $11,17,22,23$ \\
\hline Kielmeyera coriacea Mart. \& Zucc. & KIELCO & A & $\operatorname{sim}$ & AV & zoo & anem & $\mathrm{D}$ & $\begin{array}{c}10,11,17,19, \\
23\end{array}$ \\
\hline Leptolobium dasycarpum Vogel & LEPTDA & A & $\operatorname{sim}$ & AV & zoo & anem & $\mathrm{D}$ & 22,23 \\
\hline Machaerium opacum Vogel & MACHOP & A & $\operatorname{sim}$ & AV & zoo & anem & SV & 23 \\
\hline Maprounea guianensis Aubl. & MAPRGU & A & não & AV & ane & zooc & $\mathrm{D}$ & $7,10,24$ \\
\hline Miconia albicans (Sw.) Triana & MICOAL & A & não & $\mathrm{AB}$ & zoo & zooc & SV & $7,8,11,15$ \\
\hline Miconia burchellii Triana & MICOBU & A & não & AV & zoo & zooc & SV & 23 \\
\hline Miconia fallax DC. & MICOFA & A & não & $\mathrm{AB}$ & zoo & zooc & SV & $7,8,11,22$ \\
\hline Mimosa claussenii Benth. & MIMOCL & A & $\operatorname{sim}$ & AV & zoo & $\begin{array}{c}\text { anem } \\
\text { zooc }\end{array}$ & $\mathrm{D}$ & 23 \\
\hline Myrsine guianensis (Aubl.) Kuntze & MYRSGU & A & $\operatorname{sim}$ & AV & zoo & zooc & SV & $8,19,23$ \\
\hline Neea theifera Oerst. & NEEATH & A & $\operatorname{sim}$ & $\mathrm{AV}$ & zoo & zooc & $\mathrm{D}$ & 11,23 \\
\hline Ouratea hexasperma (A.St.-Hil.) Baill. & OURAHE & A & $\operatorname{sim}$ & AV & zoo & zooc & SV & $\begin{array}{c}7,13,17,19 \\
20,21,23\end{array}$ \\
\hline Palicourea rígida Kunth & PALIRI & A & não & AV & zoo & zooc & SV & $11,20,21,23$ \\
\hline Piptocarpha rotundifolia (Less.) Baker & PIPTRO & A & $\operatorname{sim}$ & AV & zoo & anem & $\mathrm{D}$ & $11,17,20,23$ \\
\hline Plenckia populnea Reissek & PLENPO & A & $\operatorname{sim}$ & AV & zoo & anem & SV & $11,17,23$ \\
\hline Pouteria ramiflora (Mart.) Radlk. & POUTRA & A & nao & AV & zoo & zooc & $\mathrm{D}$ & $7,11,17,23$ \\
\hline Protium ovatum Engl. & PROTOV & $\mathrm{L}$ & não & $\mathrm{AB}$ & zoo & zooc & SV & $2,7,20$ \\
\hline Psidium laruotteanum Cambess. & PSIDLA & A & $\operatorname{sim}$ & AV & zoo & zooc & $\mathrm{D}$ & $7,11,23$ \\
\hline Qualea parviflora Mart. & QUALPA & A & não & AV & zoo & anem & $\mathrm{D}$ & $\begin{array}{c}11,14,17,19 \\
21,23\end{array}$ \\
\hline Roupala montana Aubl. & ROUPMO & A & $\operatorname{sim}$ & AV & zoo & anem & SV & $3,11,23$ \\
\hline $\begin{array}{l}\text { Schefflera macrocarpa (Cham. \& } \\
\text { Schltdl.) Frodin }\end{array}$ & SHEFMA & $\mathrm{A}$ & $\operatorname{sim}$ & AV & zoo & zooc & SV & $11,19,23$ \\
\hline Strychnos pseudoquina A.St.-Hil. & STRYPS & A & $\operatorname{sim}$ & AV & zoo & zooc & $\mathrm{D}$ & $11,13,17,23$ \\
\hline $\begin{array}{l}\text { Stryphnodendron adstringens (Mart.) } \\
\text { Coville }\end{array}$ & STRYAD & A & $\operatorname{sim}$ & AV & zoo & auto zoo & $\mathrm{D}$ & $8,20,22,23$ \\
\hline Styrax ferrugineus Nees \& Mart. & STYRFE & A & $\operatorname{sim}$ & AV & zoo & zooc & SV & $11,19,22,23$ \\
\hline $\begin{array}{l}\text { Tachigali subvelutina (Benth.) Oliveira- } \\
\text { Filho }\end{array}$ & TACHISU & A & $\operatorname{sim}$ & AV & zoo & anem & SV & $11,17,23$ \\
\hline $\begin{array}{l}\text { Tocoyena formosa (Cham. \& Schltdl.) } \\
\text { K.Schum. }\end{array}$ & TOCOFO & A & $\operatorname{sim}$ & AV & zoo & zooc & $\mathrm{D}$ & $7,11,23$ \\
\hline Vochysia elliptica Mart. & VOCHEL & A & $\operatorname{sim}$ & AV & zoo & anem & SV & $19,20,23$ \\
\hline Zeyheria montana Mart. & ZEYHMO & A & não & AV & zoo & anem & SV & 22,23 \\
\hline
\end{tabular}

Notas: Casca $=$ tipo de casca, $\mathrm{L}=$ casca lisa, $\mathrm{A}=$ casca áspera $\mathrm{REB}=$ capacidade para rebrotar; $\mathrm{FV}=$ forma de vida, $\mathrm{AV}=$ árvore, $\mathrm{AB}=$ arbusto; $\mathrm{POL}=$ síndrome de polinização, $\mathrm{ZOO}=$ zoofilia, $\mathrm{ANE}=$ anemofilia; $\mathrm{DIS}=$ síndrome de dispersão, $\mathrm{ZOOC}=$ zoocoria, $\mathrm{ANEM}=$ anemocoria, $\mathrm{AUTO}=$ autocoria ou barocoria; Fenologia foliar = FL, D = decídua, SV = sempre-verde. Fontes: 1- Amaral et al. (2013); 2- Barbosa Filho \& Araújo (2009); 3- Carvalho et al. (2007); 4-Cavalcante et al. (2009); 5- Gottsberger (1989); 6- Guzmán \& Morales (2007); 7- Kuhlmann (2012); 8- Lenza \& Klink (2006); 9- Lorenzi et al. (2006); 10- Marquis et al. (2001); 11-Martins \& Batalha (2007); 12- Mendonça et al. (2008); 13- Mohr \& Lenza (2011); 14- Peres (2016); 15- Pilon et al. (2015); 16- Prado Junior et al. (2012); 17- Reis et al. (2012); 18- Salazar et al. (2011); 19- Scholz et al. (2008); 20- Silva (2014); 21 - Silva et al. (2009); 22- Silva et al. (2012); 23- Silva Junior (2005); 24- Silva Junior \& Pereira (2009); 25- Stefanello et al. (2009). 
Os resultados, em 1994, na Área 1, mostraram a formação de quatro grupos, com 32 espécies arbóreas (Figura 1). As espécies foram separadas pelo tipo de dispersão, zoocórica (59\%) e anemocórica (35\%), onde a maioria possuía a habilidade para rebrotar (91\%). Os grupos apresentaram as seguintes características: Grupo A (13 espécies, 113 indivíduos) - espécies com dispersão zoocórica na maioria (1 espécie com zoocoria e autocoria), árvores, caule não liso (1 liso), com capacidade para rebrotar, decíduas, e com polinização zoófila; Grupo B (4 espécies, 101 indivíduos) - espécies com dispersão zoocórica, árvores, caule não liso, com capacidade para rebrotar, sempre-verdes, e com polinização zoófila; Grupo C (3 espécies, 29 indivíduos) - espécies com dispersão zoocórica na maioria (1 com autocoria e zoocoria), árvores, caule não liso, não rebrotaram, decíduas, e com polinização zoófila; Grupo D (12 espécies, 141 indivíduos) - espécies com dispersão anemocórica, árvores, caule não liso, com capacidade para rebrotar, decíduas e sempre-verdes, e com polinização zoófila.

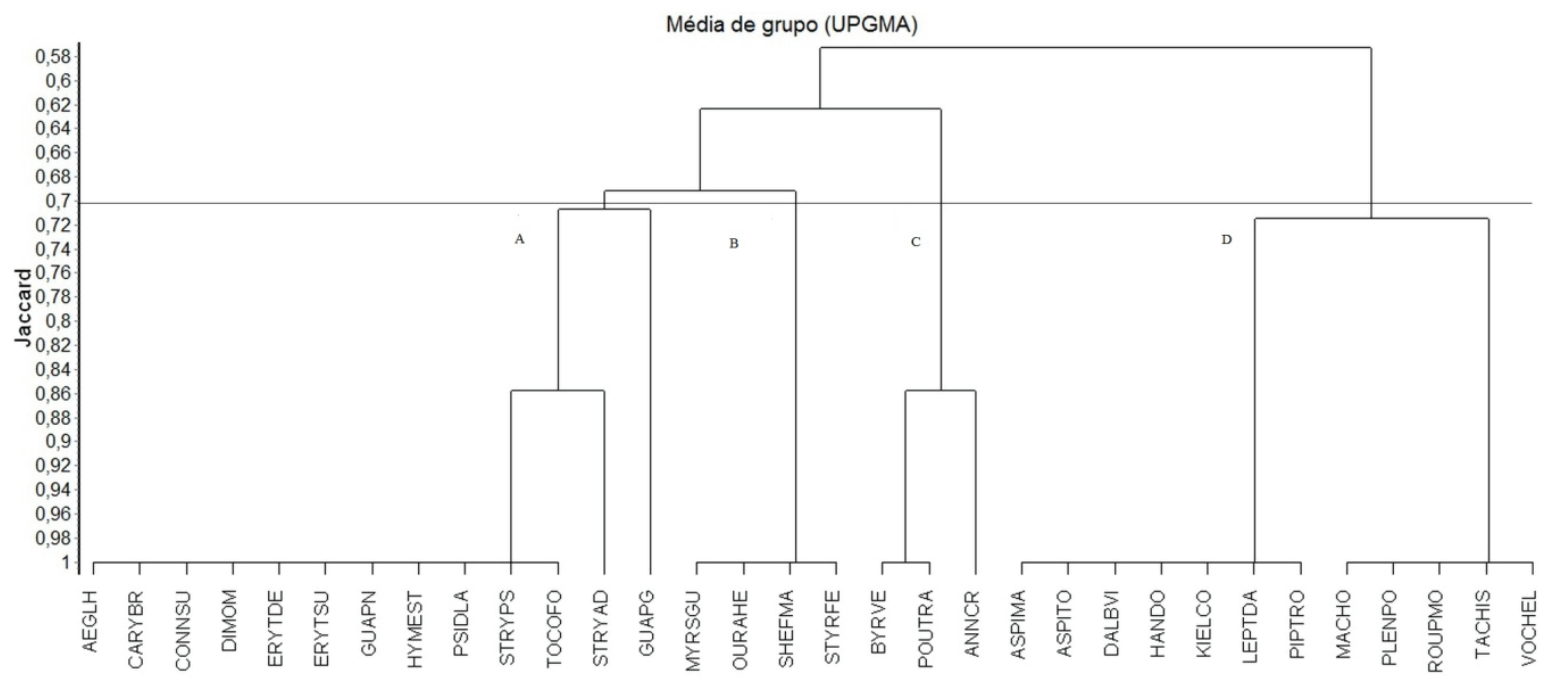

Figura 1. Dendrograma de similaridade pelo método UPGMA, utilizando o índice de Jaccard, mostrando a formação de grupos funcionais para espécies arbóreo-arbustivas de Cerrado sentido restrito em 1994 na Área 1, em Planaltina, DF, com queimadas bienais em agosto de 1988, 1990 e 1992. Correlação cofenética = 0,86.

Na Área 2, em 1994, formaram-se quatro grupos, mas com uma espécie que ficou isolada (Protium ovatum) (Figura 2). Foram incluídas 34 espécies, entre árvores e arbustos de caule com casca lisa e áspera (maioria) e todos com polinização zoófila. Os grupos foram divididos principalmente pelo tipo de dispersão zoocórica (60\%) e anemocórica (37\%), mas com uma espécie, Stryphnodendron adstringens, tendo dispersão barocórica e por animais. Desta forma, os grupos A, C e E incluíram espécies zoocóricas e os grupos B e D anemocóricas. O Grupo A foi formado, principalmente, por espécies com capacidade para rebrotar; o Grupo B com espécies que rebrotam; e os grupos C, D e E com espécies que não rebrotam. Os grupos apresentaram as seguintes características: Grupo A (17 espécies, 526 indivíduos) - espécies com dispersão zoocórica na maioria (uma espécie com zoocoria e autocoria), árvores, caule com casca não lisa na maioria (uma com caule liso), espécies com capacidade para rebrotar (uma não rebrotou), decíduas e sempre-verdes, e com polinização zoófila; Grupo B (11 espécies, 266 indivíduos) - espécies com dispersão anemocórica, árvores, caule não liso, com capacidade para rebrotar, decíduas e sempre-verdes, e com polinização zoófila; Grupo C (3 espécies, 36 indivíduos) - espécies com dispersão zoocórica, árvore e arbusto, com caule não liso, não rebrotaram, decíduas, e com polinização zoófila; Grupo D (2 espécies, 15 indivíduos) - espécies com dispersão anemocórica, árvore e arbusto, com caule não liso, não rebrotaram, sempre-verdes, e com polinização zoófila; Grupo E (1 espécie isolada, 9 indivíduos) - com dispersão zoocórica, arbusto, caule liso, não rebrotou, sempre-verde, e com polinização zoófila. 
Em 2012, na Área 1, os grupos formados incluíram 47 espécies, e foram divididos, principalmente, entre espécies com capacidade de rebrotar (64\%), que não rebrotam (36\%), e o tipo de casca lisa (11\%) e áspera (89\%). Formaram-se grupos com as seguintes características (Figura 3): Grupo A (20 espécies, 528 indivíduos) - espécies com capacidade para rebrotar, árvores, com casca não lisa na maioria (uma casca lisa), decíduas, zoofilia, zoocoria (uma com barocoria ou autocoria e zoocoria), anemocoria; Grupo B (9 espécies, 421 indivíduos) - espécies com capacidade para rebrotar, árvores, casca não lisa, sempre-verdes, zoofilia, anemocoria e zoocoria; Grupo C (8 espécies, 72 indivíduos) - espécies que não rebrotaram, árvores, casca não lisa, decídua, zoofilia (1 com anemofilia), zoocoria (uma com autocoria ou barocoria e zoocoria), anemocoria; Grupo D (7 espécies, 127 indivíduos) - espécies que não rebrotaram, arbustos (maioria) e árvores (2), casca não lisa (maioria) e casca lisa (1), sempre-verdes (maioria) e decídua (1), zoofilia, zoocoria; Grupo E (3 espécies, 83 indivíduos) - espécies que não rebrotaram (1 rebrotou), arbustos, casca lisa, decíduas, zoofilia, zoocoria (2) e uma com autocoria ou barocoria.

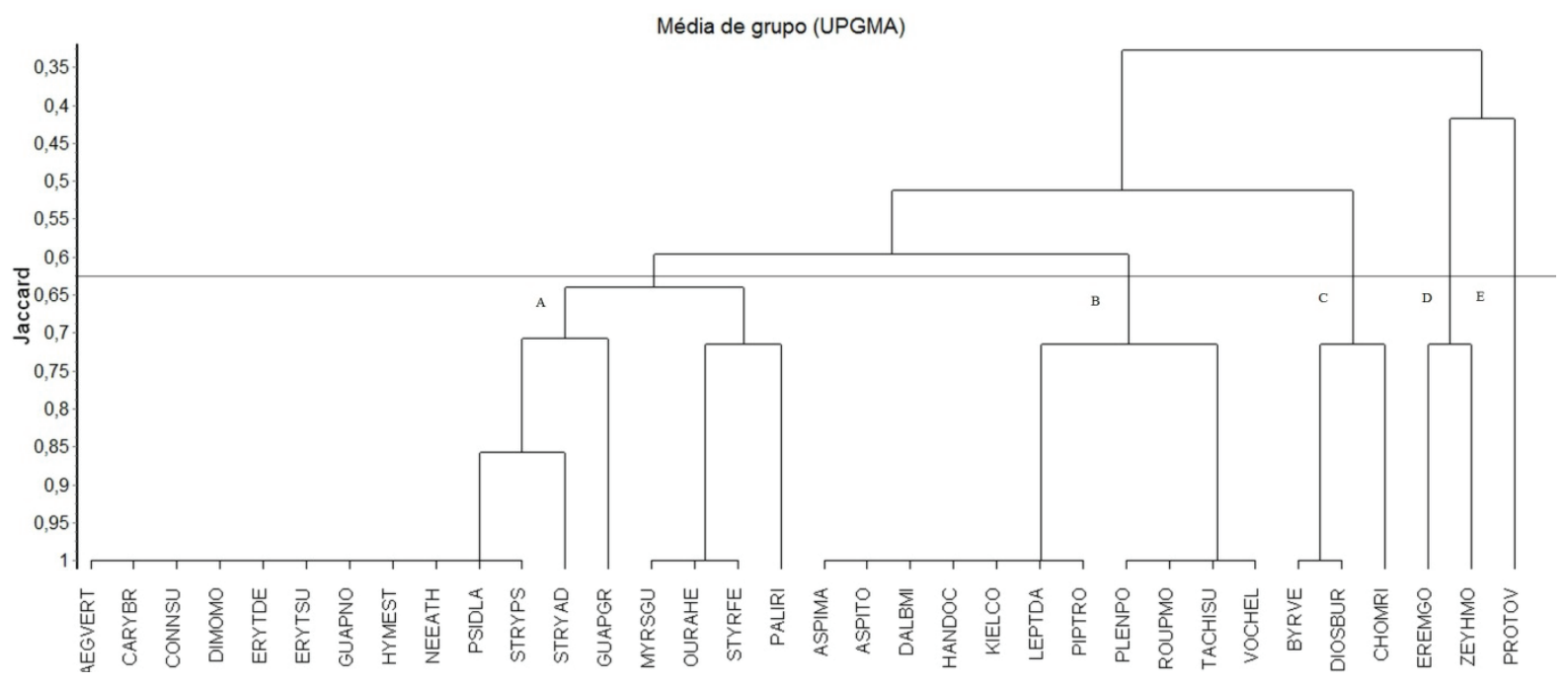

Figura 2. Dendrograma de similaridade pelo método UPGMA, utilizando o índice de Jaccard, mostrando a formação de grupos funcionais para espécies arbóreo-arbustivas de Cerrado sentido restrito em 1994 na Área 2, em Planaltina, DF, protegida contra o fogo no período de 1988 a julho de 1994. Correlação cofenética $=0,87$.

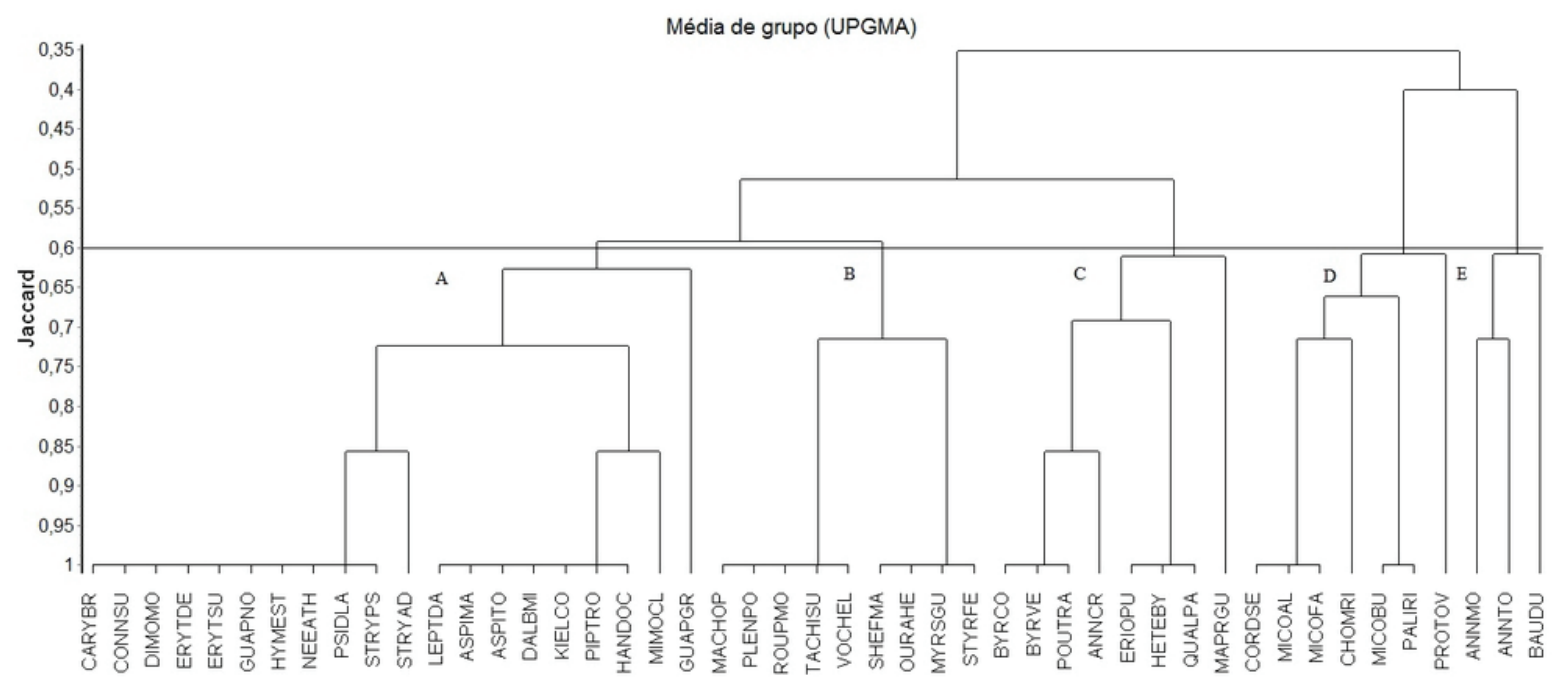

Figura 3. Dendrograma de similaridade pelo método UPGMA, utilizando o índice de Jaccard, mostrando a formação de grupos funcionais para espécies arbóreo-arbustivas de Cerrado sentido restrito em 2012 na Área 1 , em Planaltina, DF, com queimadas bienais em agosto de 1988, 1990 e 1992, fogo acidental em agosto de 1994 e com exclusão do fogo de setembro de 1994 a 2012. Correlação cofenética $=0,84$. 
$\mathrm{Na}$ Área 2, em 2012, formaram-se cinco grupos, com 37 espécies, entre árvores e arbustos e polinização zoófila. A característica mais marcante foi o tipo de casca (lisa e áspera). A deciduidade também foi outra característica importante. Assim, os grupos foram divididos inicialmente pelo tipo de casca. Os grupos A, $\mathrm{B}$ e $\mathrm{C}$ incluíram espécies com casca não lisa, decíduas (A) e sempre-verdes (B, C). Os grupos D e E incluíram espécies com casca lisa, decíduas (E) e decíduas e sempre-verdes (D). Os grupos A, B e D incluíram espécies com dois tipos de dispersão. Assim, formaramse grupos com as seguintes características (Figura 4): Grupo A (20 espécies, 382 indivíduos) - com espécies com casca não lisa, árvores, decíduas, com capacidade para rebrotar na maioria (2 não rebrotam), zoofilia, anemocoria, zoocoria (uma com autocoria ou barocoria e zoocoria); Grupo B (8 espécies, 477 indivíduos - com espécies com casca não lisa, árvores, sempre-verdes, com capacidade para rebrotar, zoofilia, zoocoria e anemocoria; Grupo C (4 espécies, 120 indivíduos) com espécies com casca não lisa, árvores e arbustos, sempre-verdes, não rebrotam, zoofilia, zoocoria; Grupo D (3 espécies, 108 indivíduos) - com espécies com casca lisa, arbustos, decíduas e sempre-verdes, não rebrotam, zoofilia, autocoria ou barocoria e zoocoria; Grupo E ( 2 espécies, 65 indivíduos): espécies com casca lisa, arbusto e árvore, decíduas, com capacidade para rebrotar, zoofilia, zoocoria.

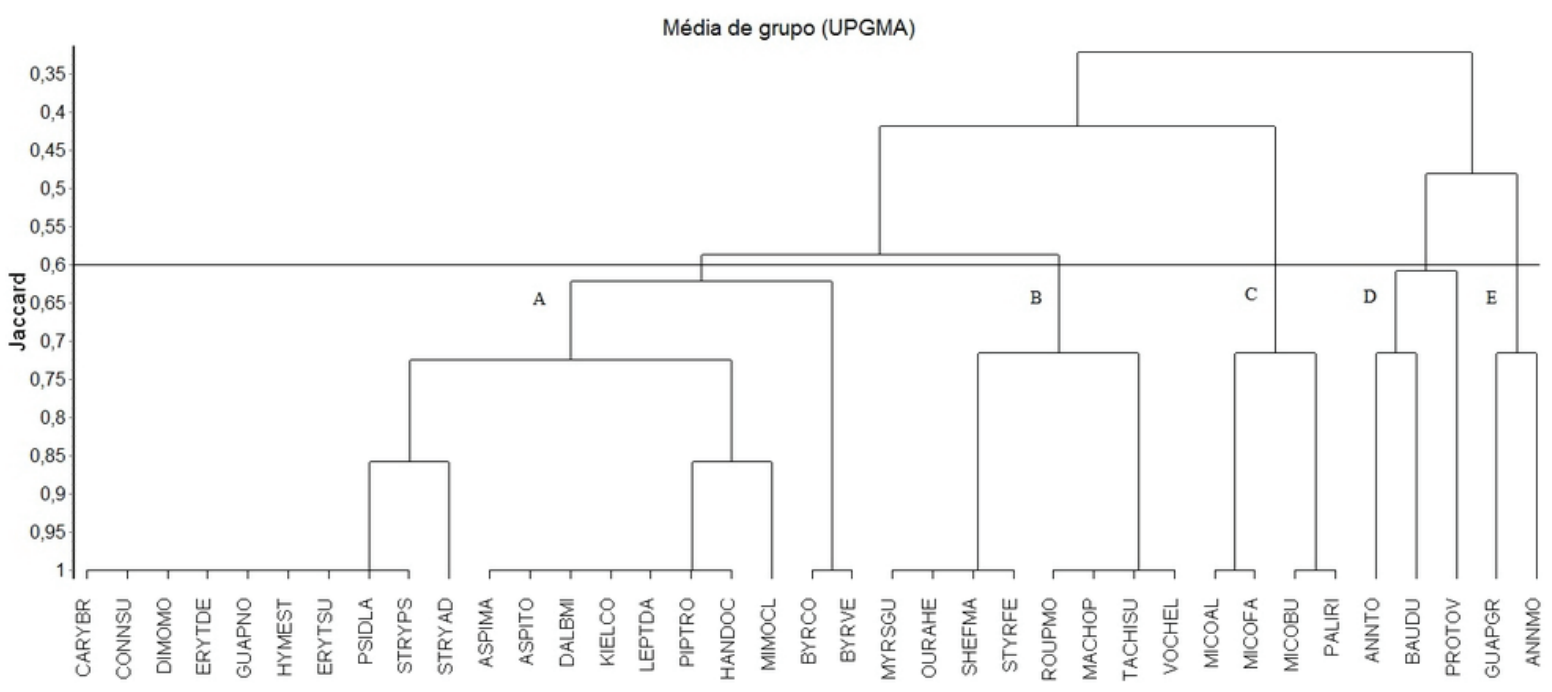

Figura 4. Dendrograma de similaridade pelo método UPGMA, utilizando o índice de Jaccard, mostrando a formação de grupos funcionais para espécies arbóreo-arbustivas de Cerrado sentido restrito em 2012, na Área 2, em Planaltina, DF, protegida contra o fogo no período de 1988 a julho de 1994, fogo acidental em agosto de 1994, e com exclusão do fogo de setembro de 1994 a 2012. Correlação cofenética $=0,87$.

\section{Discussão}

As duas áreas mostraram diferenças nos grupos formados em cada ano. Em 1994, na Área 1, as espécies possuíam, principalmente, características relacionadas à reprodução e à resistência diante do distúrbio fogo, com alguns atributos similares, tais como o hábito de crescimento (todas eram arbóreas), o tipo de casca áspera (somente uma lisa), e a polinização (todas zoófilas). A forma de vida, possivelmente, esteve associada ao vigor competitivo e à resposta aos distúrbios (Cornelissen et al., 2003; Zilli et al., 2014). O fato das espécies arbóreas terem variação no sistema radicular, podendo ser capazes de retirar água tanto de regiões profundas quanto de superficiais (Jackson et al., 1999; Goldstein et al., 2008) pode justificar o favorecimento desse atributo na área com queimadas frequentes. Por outro lado, as principais características adaptativas das espécies estavam ligadas ao isolamento térmico dos tecidos internos, com a suberização do tronco e ramos, e à habilidade para rebrotar de regiões subterrâneas (Cianciaruso et al., 2012).

O tipo de casca tem sido mencionado como essencial para a sobrevivência de algumas espécies do Cerrado diante das queimadas (Vale \& Elias, 2014). E, além da espessura, a arquitetura externa da casca morta também 
é citada como um fator importante para a proteção do câmbio (Vale et al., 2009), que pode influenciar o efeito isolante da casca, devido às irregularidades na sua superfície (Mazzoni-Viveiros \& Costa, 2003). Possivelmente, essas características também podem ter colaborado para a diminuição da mortalidade das plantas pelo fogo (Silva et al., 2013), pois, dentre as espécies, somente Guapira graciliflora apresentou casca lisa, mas também capacidade para rebrotar.

Apesar da característica determinante na formação dos diferentes grupos ter sido o tipo de dispersão (zoocórica e anemocórica), a capacidade de rebrotar também foi importante, pois somente três espécies não apresentaram esse atributo. A reprodução sexuada depende de vetores da polinização (Oliveira \& Gibbs, 2000; Silva et al., 2012) e, na área analisada, apesar de haver predomínio de espécies polinizadas e dispersas por animais, a capacidade de rebrotar foi uma estratégia de resistência ao distúrbio fogo entre as espécies estudadas. No grupo das espécies zoocóricas (A, B, C), aquelas que não rebrotaram eram minoria, decíduas, e as que rebrotaram eram decíduas ou sempre-verdes. O grupo A, mais rico em espécies e mais diverso em atributos, incluiu as espécies zoocóricas, com capacidade para rebrotar e casca áspera, indicando elevada contribuição para a manutenção da comunidade diante do distúrbio. De forma geral, as síndromes de polinização e dispersão estão ligadas à habilidade de recolonização diante de distúrbios (Cianciaruso et al., 2012; Pérez-Harguindeguy et al., 2013), e as espécies zoocóricas, possivelmente, seguiram o padrão de dispersão dos diásporos durante o período chuvoso, com os frutos sendo atrativos por períodos mais prolongados (Batalha et al., 1997; Lenza \& Klink, 2006) e tendo menos danos relacionados às queimadas.

As plantas decíduas, com maior número de espécies e mais abundantes em relação às sempre-verdes, provavelmente, foram menos vulneráveis à ação do fogo por, geralmente, perderem as folhas na seca (Lucena et al., 2015) e também devido às diferenças no uso da água (Lenza \& Klink, 2006; Pirani et al., 2009). As plantas decíduas evitam a seca pela produção de folhas pouco longevas e apresentam taxas insignificantes de transpiração no período seco; espécies sempre-verdes toleram a seca, com elevada longevidade foliar e fluxo transpiracional por todo o ano (Souza et al., 2015). Dessa forma, aliado à estas estratégias e ao intervalo entre as queimadas, a reprodução das espécies decíduas, possivelmente, também foi favorecida pela habilidade de rebrotar apresentado pela maioria delas.

O grupo D, mais abundante, incluiu espécies anemocóricas, decíduas ou sempre-verdes, e capazes de rebrotar. A deciduidade e a capacidade para rebrotar em espécies do Cerrado são mencionadas como características adaptativas ao fogo frequente (Silvério et al., 2015). A anemocoria pode ser consequência da sazonalidade climática do Cerrado e da deciduidade foliar, pois espécies decíduas, geralmente, perdem suas folhas durante o período seco, facilitando a dispersão dos diásporos, pela abertura dos frutos com a baixa umidade, pelo aumento da velocidade dos ventos e pela redução da cobertura das folhas (Batalha \& Mantovani, 2000; Lenza \& Klink, 2006; Pirani et al., 2009; Reis et al., 2012). E, como consequência das três queimadas ocorridas no período seco, o fogo pode ter tido efeitos negativos na fenologia vegetativa deste grupo como um todo, mesmo nas decíduas que perderam as folhas no final da estação seca (Silvério et al., 2015), e na reprodução sexuada, pela queima dos frutos e sementes. Ainda assim, possivelmente, algumas espécies foram favorecidas pela propagação vegetativa, já que todas apresentaram habilidade para rebrotar.

A proteção contra a ação do fogo, na Área 2, proporcionou a formação de grupos diferenciados em comparação com a Área 1, em 1994. O grupo das espécies zoocóricas (A, C) compreendeu aquelas capazes de rebrotar (decíduas e sempre-verdes), as que não rebrotaram (decíduas) e a inclusão do hábito arbustivo. O grupo das anemocóricas (B, D) também foi dividido entre espécies que rebrotaram (decíduas e sempre-verdes). Aquelas que não rebrotaram (sempreverdes) formaram um grupo que não ocorreu na Área 1, indicando que a ausência do fogo favoreceu estas espécies.

Houve acréscimo de atributos, como a forma de vida arbustiva, bem como a formação de um grupo com espécies anemocóricas que não rebrotaram, indicando a presença de outras estratégias que não estavam relacionadas com a resistência ao fogo e sugerindo maior diversidade de caracteres funcionais. A maioria das espécies zoocóricas apresentou caule com casca áspera, e todas as anemocóricas possuíam casca áspera, mostrando que é uma característica relevante, com importante função na proteção da planta, não somente das queimadas (Vale et al., 2009), mas também, provavelmente, do ataque de patógenos, de herbívoros e das secas (Cornelissen et al., 2003).

Pesq. flor. bras., Colombo, v. 37, n. 91, p. 285-298, jul./set. 2017 
Em ambientes onde a sazonalidade na precipitação é pronunciada, a época seca pode determinar a fenologia, limitando o crescimento e a reprodução das plantas (Marques \& Oliveira, 2004). E, nesta área, protegida da ação do fogo, onde a fenologia foliar variou nos diferentes grupos, mas com maior percentual de espécies decíduas $(67,7 \%)$ do que sempre-verdes $(32,3 \%)$, a co-ocorrência destas espécies pode estar relacionada à diferentes estratégias de utilização da água e resistência à seca (Pirani et al., 2009; Souza et al., 2015). Na maioria das espécies do Cerrado, a expansão de folhas novas ocorre durante a época seca (Oliveira \& Gibbs, 2000; Medeiros \& Miranda, 2008), sendo também comumente observada a perda das folhas das espécies decíduas nesta estação (Lucena et al., 2015). De forma geral, espécies sempre-verdes possuem traços foliares relacionados à tolerância à seca e espécies decíduas possuem estratégias de evitação à seca (Souza et al., 2015).

Por outro lado, no Cerrado as espécies anemocóricas seguem, geralmente, um padrão de dispersão dos frutos de forma mais eficiente na época seca (Batalha et al., 1997; Batalha \& Mantovani, 2000), justificando o maior número de grupos com anemocoria na Área 2, em relação à Área 1, que teve somente um grupo, e dando ênfase a essas espécies na manutenção da comunidade. A maior abundância das espécies anemocóricas e decíduas nesta área também sugere que o fogo prejudicou a reprodução sexuada destas plantas na Área 1. Além disso, em relação à habilidade para rebrotar, houve maior percentual de espécies que não rebrotam (21\%) em comparação à Área 1 (9\%). A formação de dois grupos com espécies que não rebrotam também reforça a inclusão de algumas espécies e a relevância das síndromes de polinização e de dispersão no sucesso reprodutivo das plantas na Área 2 (Zilli et al., 2014), com o predomínio de zoofilia (100\%) e a variação na dispersão, com espécies zoocóricas (62\%) e anemocóricas (38\%).

Em 2012, na Área 1, após quatro ocorrências de fogo e 18 anos sem queimar, houve modificação dos grupos, desde 1994. Nas análises de 1994 havia 32 espécies arbóreas, com casca áspera na maioria (com uma lisa) e aquelas que não rebrotaram eram decíduas e zoocóricas. Mas, em 2012 formaram-se cinco grupos, com 47 espécies, e a inclusão de 15 espécies e de outros atributos que não caracterizam resistência ao fogo, como a forma de vida arbustiva, o maior número de espécies que não rebrotaram e de casca lisa, além da polinização anemófila. O grupo das espécies que rebrotaram foi dividido entre espécies decíduas (A) e sempre-verdes (B), com mais de um tipo de dispersão. E o grupo das espécies que não rebrotaram foi dividido em decíduas com anemocoria, zoocoria e autocoria $(\mathrm{C})$, em decíduas e sempre-verdes com zoocoria (D), e em decíduas (arbustos de casca lisa) com zoocoria e autocoria (E). A maioria das espécies teve polinização por animais, com uma (Maprounea guianensis) sendo polinizada pelo vento (anemofilia).

A característica mais marcante para a formação dos grupos esteve relacionada à habilidade para rebrotar, sendo que em três, dos cinco grupos, as espécies não rebrotaram. A capacidade de rebrotar é considerada um atributo importante na história de vida de algumas plantas do Cerrado (Ribeiro et al., 2012) e, desta forma, estes resultados alcançados nesse trabalho corroboram com o fato de que esta habilidade promove a persistência de algumas espécies após distúrbios (Cianciaruso et al., 2012; Silva et al., 2013), como queimadas e corte de árvores (Cornelissen et al., 2003). A capacidade de rebrotar após queimadas foi observada em $64 \%$ das espécies estudadas em 2012, sugerindo a importância deste atributo e, também, que a exclusão do fogo por 18 anos favoreceu a entrada de espécies que não rebrotam, em relação ao período 1988-1994, quando todas as espécies rebrotaram. Assim, a proteção contra o fogo promoveu a entrada de espécies sensíveis (Hoffmann, 1998), com a inclusão de mais espécies com casca lisa, que não rebrotam, e o maior número de espécies de hábito arbustivo, indicando maior diversidade de traços funcionais (Cianciaruso et al., 2009).

Na Área 2, após 18 anos sem queimar, em 2012, e com histórico distinto de fogo, em relação à Área 1, a característica mais marcante na separação dos grupos foi o tipo de casca lisa $(13,5 \%)$ e áspera $(86,5 \%)$, evidenciando a importância da casca na proteção dos tecidos internos dos caules, tanto das altas temperaturas durante as queimadas (Silva et al., 2011) quanto das secas (Cornelissen et al., 2003).

Dentro do grupo com casca áspera, a maioria das espécies decíduas apresentou capacidade para rebrotar (A), mas quanto às sempre-verdes algumas apresentaram esta habilidade (B) e outras não (C). E no grupo das espécies com casca lisa, as espécies que não rebrotavam eram decíduas ou sempre-verdes (D), e aquelas capazes de rebrotar eram decíduas (E). A capacidade de rebrotar a partir da base do caule e de órgãos subterrâneos está relacionada ao vigor competitivo e à persistência das 
espécies após distúrbios (Cianciaruso et al., 2012; Silva et al., 2013), como queimadas e corte de árvores (Cornelissen et al., 2003). Esta característica foi essencial para a manutenção das espécies na comunidade estudada, sendo observada em $76 \%$ das espécies, entre decíduas e sempre-verdes.

As plantas decíduas apresentaram maior número de espécies $(65 \%)$ e menor número de indivíduos. No entanto, as plantas perenifólias foram mais abundantes, mas representadas por $35 \%$ do total das espécies. Nessa área, a fenologia foliar pode estar relacionada à luminosidade, mas a co-ocorrência de espécies decíduas e sempre-verdes também pode ser um indicativo de diferentes estratégias quanto ao uso de água e resistência à seca (Souza et al., 2015). A queda das folhas na estação seca pode proporcionar a abertura do dossel, e ter consequências na regeneração de algumas espécies (Vale et al., 2013). Geralmente, as espécies decíduas evitam a seca (Souza et al., 2015), apresentando períodos muito curtos de exposição foliar, fora do pico principal das folhas de espécies mais competitivas (Prado Junior et al., 2012) e tendo a abscisão foliar como um meio de reduzir as barreiras que dificultam a dispersão (Pilon et al., 2015). As perenifólias, que geralmente mantêm as folhas durante todo ano, toleram a seca (Souza et al., 2015) e, também, podem desfavorecer algumas espécies exigentes de luz (Vale et al., 2013), tendo consequências na regeneração de algumas espécies.

O fogo pode agir como um filtro ambiental, estruturando as características funcionais, reunindo espécies com características funcionais semelhantes (Silva \& Batalha, 2010; Cianciaruso et al., 2012) e eliminando espécies com pouca ou nenhuma característica de adaptação a este distúrbio (Medeiros \& Miranda, 2005; Silva et al., 2011; Zilli et al., 2014). Assim, as queimadas frequentes podem reduzir a diversidade funcional de uma comunidade (Cianciaruso et al., 2010; Silva et al., 2011). Na avaliação da formação dos grupos funcionais presentes nas duas áreas com diferentes históricos de queimadas, em 1994 e em 2012, os resultados mostraram diferenças nas duas áreas e épocas estudadas, e indicaram que a maior frequência do fogo, na Área 1, em 1994, reuniu espécies funcionalmente semelhantes. Por outro lado, o tempo de exclusão do fogo favoreceu algumas espécies e a ocorrência de maior diversidade de atributos em 2012.

\section{Conclusões}

A maior frequência do fogo em área de Cerrado senso restrito favoreceu espécies funcionalmente semelhantes, com menor diversidade de atributos, destacando-se a capacidade para rebrotar, a casca áspera e a forma de vida arbórea.

A proteção contra a ação do fogo favoreceu a entrada de algumas espécies e a maior diversidade de atributos, com a inclusão da forma de vida arbustiva e da polinização anemófila, e com o aumento das espécies com casca lisa e sem capacidade para rebrotar.

\section{Referências}

Amaral, A. G. et al. Vascular flora in dry-shrub and wet grassland Cerrado seven years after a fire, Federal District, Brazil. Check List, v. 9, n. 3, p. 487-503, 2013. DOI: 10.15560/9.3.487.

Araújo, M. M. et al. Análise de agrupamento em remanescente de floresta ombrófila mista. Ciência Florestal, v. 20, n. 1, p. 1-18, 2010. DOI: $10.5902 / 198050981755$.

Barbosa-Filho, W. G. \& Araújo, A. C. Fenologia de floração e síndromes de polinização na serra de Maracaju, Mato Grosso do Sul. In: ENCONTRO DE INICIAÇÃO CIENTÍFICA 10., 2009, Campo Grande. Anais... Campo Grande: UFMS, 2009. 19 p.

Batalha, M. A. et al. Variações fenológicas das espécies do cerrado em Emas (Pirassununga, SP). Acta Botanica Brasilica, v. 11, p. 61-78, 1997. DOI: 10.1590/S0102-33061997000100007.

Batalha, M. A. \& Mantovani, W. Reproductive phenological patterns of cerrado plant species at the Pé-de-Gigante Reserve (Santa Rita do Passa Quatro, SP, Brazil): a comparison between the herbaceous and woody floras. Revista Brasileira de Biologia, v. 60, n. 1, p. 129-145, 2000. DOI: 10.1590/S0034-71082000000100016.

Bawa, K. S. Plant-pollinator interactions in tropical rain forests. Annual Review of Ecology System, v. 21, p. 399-422, 1990. DOI: 10.1146/annurev.ecolsys.21.1.399.

Carvalho, A. P. F. et al. Variações sazonais nas concentrações de pigmentos e nutrientes em folhas de espécies de Cerrado com diferentes estratégias fenológicas. Revista Brasileira de Botânica, v. 30, n. 1, p. 19-27, 2007. DOI: 10.1590/S0100-84042007000100003.

Cavalcante, T. R. M. et al. Polinização e formação de frutos em araticum. Bragantia, v. 68, n. 1, p. 13-21, 2009. DOI: 10.1590 / S0006-87052009000100002.

Cianciaruso, M. V. et al. Aboveground biomass of functional groups in the ground layer of savannas under different fire frequencies. Australian Journal of Botany, v. 58, n. 3, p. 169-174, 2010. DOI: 10.1071/BT09136.

Cianciaruso, M. V. et al. Diversidades filogenética e funcional: novas abordagens para a ecologia de comunidades. Biota Neotropica, v. 9, n. 3, p. 93-193, 2009. DOI: 10.1590/S1676-06032009000300008. 
Cianciaruso, M. V. et al. The influence of fire on phylogenetic and functional structure of woody savannas: moving from species to individuals. Perspectives in Plant Ecology, Evolution and Systematics, v. 14, p. 205-216, 2012. DOI: 10.1016/j. ppees.2011.11.004.

Cornelissen, J. H. C. et al. A handbook of protocols for standardised and easy measurement of plant functional traits worldwide. Australian Jounal of Botany, v. 51, p. 335-380, 2003. DOI: 10.1071/ BT02124.

Coutinho, L. M. Fire in the ecology of the Brazilian Cerrado. In: GOLDAMMER, J. G. (Ed.). Fire in the tropical biota: ecosystem processes and global challenges. Berlin: Springer-Verlag, 1990. p. 82-105. (Ecological Studies, v. 8).

Deng A. F. et al. Identification of functional groups in an old-growth tropical montane rain forest on Hainan Island, China. Forest Ecology and Management, v. 255, n. 5-6, p. 1820-1830, 2008. DOI: 10.1016/j.foreco.2007.12.004.

Goldstein, G. et al. Water economy of Neotropical savanna trees: six paradigms revisited. Tree Physiology, v. 28, p. 395-404, 2008. DOI: 10.1093/treephys/28.3.395.

Gottsberger, G. Beetle pollination and flowering rhythm of Annona spp. (Annonaceae) in Brazil. P1ant Systematics and Evolution, v. 167, p. 165-187, 1989. DOI: 10.1007/BF00936404.

Guzmán, G. G. \& Morales, E. Life-history strategies of plant pathogens: distribution patterns and phylogenetic analysis. Ecology, v. 88 , n. 3, p. 589-596, 2007. DOI: 10.1890/05-1174.

Heringer, I. \& Jacques, A. V. A. Adaptação das plantas ao fogo: enfoque na transição floresta - campo. Ciência Rural, v. 31, n. 6, p. 1085-1090, 2001. DOI: 10.1590/S0103-84782001000600028.

Hoffmann, W. A. Post-burn reproduction of woody plants in a Neotropical savanna: the relative importance of sexual and vegetative reproduction. Journal of Applied Ecology, v. 35, p. 422-433, 1998. DOI: 10.1046/j.1365-2664.1998.00321.x.

Jackson, P. C. et al. Partitioning of soil water among tree species in a Brazilian Cerrado ecosystem. Tree Physiology, v. 19, p. 717-724, 1999. DOI: $10.1093 /$ treephys/19.11.717.

Kuhlmann, M. Frutos e sementes atrativos para a fauna: guia de campo. Brasília, DF: Rede de Sementes, 2012. 360 p.

Lenza, E. \& Klink, C. A. Comportamento fenológico de espécies lenhosas em um cerrado sentido restrito de Brasília, DF. Revista Brasileira de Botânica, v. 29, n. 4, p. 627-638, 2006. DOI: 10.1590/ S0100-84042006000400013.

Lorenzi, H. et al. Frutas brasileiras e exóticas cultivadas (de consumo in natura). São Paulo: Plantarum, 2006. 640 p.

Lucena, I. C. et al. A deciduidade foliar indica a vulnerabilidade de espécies lenhosas ao fogo. Revista Árvore, v. 39, n. 1, p. 59-68, 2015. DOI: $10.1590 / 0100-67622015000100006$.

Marques, M. C. M. \& Oliveira, P. E. A. M. Fenologia de espécies do dossel e do sub-bosque de duas Florestas de Restinga na Ilha do Mel, Sul do Brasil. Revista Brasileira de Botânica, v. 27, n. 4, p. 713-723, 2004. DOI: 10.1590/S0100-84042004000400011.
Marquis, R. J. et al. Patterns and correlates of interspecic variation in foliar insect herbivory and pathogen attack in Brazilian cerrado. Journal of Tropical Ecology, v. 17, p. 127-148, 2001. DOI: 10.1017/ S0266467401001080.

Martins, F. Q. \& Batalha, M. A. Vertical and horizontal distribution of pollination systems in Cerrado fragments of Central Brazil. Brazilian Archives of Biology and Technology, v. 50, n. 3, p. 503-514, 2007. DOI: $10.1590 /$ S1516-89132007000300016.

Mazzoni-Viveiros, S. C. \& Costa, C. G. Periderme. In: AppezzatoDa-Glória, B. \& Carmello-Guerreiro, S. M. (Ed.). Anatomia vegetal. Viçosa, MG: UFV, 2003. p. 237-263.

Medeiros, M. B. \& Miranda, H. S. Mortalidade pós-fogo em espécies lenhosas de campo sujo submetido a três queimadas prescritas anuais. Acta Botânica Brasilica, v. 19, n. 3, p. 493-500, 2005. DOI: $10.1590 / \mathrm{S} 0102-33062005000300009$.

Medeiros, M. B. \& Miranda, H. S. Post-fire resprouting and mortality in cerrado woody plant species over a three-year period. Edinburgh Journal of Botany, v. 65, n. 1, p. 53-68, 2008. DOI: 10.1017/ S0960428608004708.

Mendonça, R. C. et al. Flora vascular do Cerrado. In: Sano, S. M. \& Almeida, S. P. (Ed.). Cerrado: ambiente e flora. Brasília, DF: EMBRAPA-CPAC, 2008. p. 289-556.

Miranda, H. S. \& Sato, M. N. Efeitos do fogo na vegetação lenhosa do Cerrado. In: Scariot, A. et al. (Org.). Cerrado: ecologia, biodiversidade e conservação. Brasília, DF: Ministério do Meio Ambiente, 2005. p. 95-103.

Mohr, A. \& Lenza, E. Síndromes de polinização de uma comunidade lenhosa em área de Cerrado Sentido Restrito, Ribeirão Cascalheira, Mato Grosso. 2011. Curso de campo. Disponível em: $<$ http://www.unemat.br/prppg/ppgec/mestrado/docs/ Producoes_Curso_de_Campo_2011/Relatorios_Individuais_2011/ Adriana_Mohr_Sindromes_de_polinizacao_em_cerrado.pdf.> Acesso em: 05 dez. 2015.

Moreira, F. et al. A conceptual model of sprouting responses in relation to fire damage: an example with cork oak (Quercus suber L.) trees in Southern Portugal. Plant Ecology, v. 201, n. 1, p. 77-85, 2009. DOI: $10.1007 / \mathrm{s} 11258-008-9476-0$.

Mueller-Dombois, D. \& Ellenberg, H. Aims and methods of vegetation ecology. New York: Willey and Sons, 1974.

Muller, S. C. et al. Plant functional types of woody species related to fire disturbance in forest-grassland ecotones. Plant Ecology, v. 189, p. 1-14, 2007. DOI: 10.1007/s11258-006-9162-z.

Oliveira, P. E. \& Gibbs, P. E. Reproductive biology of woody plants in a cerrado community of the central Brazil. Flora, v. 195, p. 311329, 2000. DOI: 1016/S0367-2530(17)30990-8.

Parron, L. M. et al. Reservas ecológicas da Embrapa Cerrados: caracterização e zoneamento. Planaltina: EMBRAPA-CPAC, 1998. $80 \mathrm{p}$.

Peres, M. K. Estratégias de dispersão de sementes no bioma Cerrado: considerações ecológicas e filogenéticas. 2016. 360 f. Tese (Doutorado em Botânica) - Universidade de Brasília. 
Pérez-Harguindeguy, N. et al. New handbook for standardised measurement of plant functional traits worldwide. Australian Journal of Botany, v. 61, p. 137-234, 2013. DOI: 10.1071/BT12225.

Petchey, O. L. \& Gaston, K. J. Functional diversity: back to basics and looking forward. Ecology Letters, v. 9, n. 6, p. 741-758, 2006. DOI: 10.1111/j.1461-0248.2006.00924.x.

Pijl, L. van der. Principles of dispersal in higher plants. 3. ed. Nova Iorque: Springer Verlag, 1982.

Pilon, N. A. L. et al. Padrões fenológicos de 111 espécies de Cerrado em condições de cultivo. Hoehnea, v. 42, n. 3, p. 425-443, 2015. DOI: $10.1590 / 2236-8906-07 / 2015$.

Pirani, F. R. et al. Fenologia de uma comunidade arbórea em cerrado sentido restrito, Barra do Garças, MT, Brasil. Acta Botanica Brasílica, v. 23, n. 4, p. 1096-1109, 2009. DOI: 10.1590/S010233062009000400019.

Prado Junior, J. A. et al. Comparação florística, estrutural e ecológica da vegetação arbórea das fitofisionomias de um remanescente urbano de cerrado. Bioscience Journal, v. 28, n. 3, p. 456-471, 2012.

Reis, S. M. et al. Síndromes de polinização e dispersão de espécies lenhosas de um fragmento de cerrado sentido restrito na transição Cerrado - Floresta Amazônica. Heringeriana, v. 6, n. 2, p. 28-41, 2012.

Ribeiro, M. N. et al. Fogo e dinâmica da comunidade lenhosa em cerrado sentido restrito, Barra do Garças, Mato Grosso. Acta Botânica Brasilica, v. 26, n. 1, p. 203-217, 2012. DOI: 10.1590/ S0102-33062012000100020.

Salazar, A. et al. Timing of seed dispersal and dormancy, rather than persistent soil seed-banks, control seedling recruitment of woody plants in Neotropical savannas. Seed Science Research, v. 21, p. 103-116, 2011. DOI: 10.1017/S0960258510000413.

Salazar, A. \& Goldstein, G. Effects of fire on seedling diversity and plant reproduction (sexual vs. vegetative) in neotropical savannas differing in tree density. Biotropica, v. 46, n. 2, p. 139-147, 2014. DOI: 10.1111/btp.12090.

Santos, H. G. et al. Sistema brasileiro de classificação de solos. 3 . ed. Brasília, DF: Embrapa, 2013. 353 p.

Sartorelli, P. A. R. et al. Rebrota após fogo de espécies arbóreas de diferentes grupos fenológicos foliares em Cerrado stricto sensu. Revista Científica Eletrônica de Engenharia Florestal, v. 6, n. 10, 2007.

Sato, M. N. et al. O fogo e o estrato arbóreo do Cerrado: efeitos imediatos e de longo prazo. In: Miranda, H. S. (Org.). Efeitos do regime do fogo sobre a estrutura de comunidade de Cerrado: Projeto fogo. Brasília, DF: IBAMA, 2010. p. 77-91.

Shepherd, G. J. Manual do usuário: FITOPAC 2.1.2.85 Campinas: UNICAMP, 2010.

Scholz, F.G. et al. Plant- and stand-level variation in biophysical and physiological traits along tree density gradients in the Cerrado. Brazilian Journal of Plant Physiology, v. 20, n. 3, p. 217-232, 2008. DOI: 10.1590/S1677-04202008000300006.

Silva, C. I. et al. Distribuição vertical dos sistemas de polinização bióticos em áreas de cerrado sentido restrito no Triângulo Mineiro, MG, Brasil. Acta Botanica Brasilica, v. 26, n. 4, p. 748-760, 2012. DOI: $10.1590 / \mathrm{S} 0102-33062012000400004$.
Silva, D. M. et al. Influence of fire history and soil properties on plant species richness and functional diversity in a neotropical savanna. Acta Botanica Brasilica, v. 27, n. 3, p. 490-497, 2013. DOI: 10.1590/ S0102-33062013000300005.

Silva, D. M. et al. Os efeitos dos regimes de fogo sobre a vegetação de Cerrado no Parque Nacional das Emas, GO: considerações para a conservação da diversidade. Biodiversidade Brasileira, v. 1, n. 2, p. 26-39, 2011.

Silva, I. A. \& Batalha, M. A. Woody plant species co-occurrence in Brazilian savannas under different fire frequencies. Acta Oecologica, v. 36, n. 1, p. 85-91, 2010. DOI: 10.1016/j.actao.2009.10.004.

Silva, I. A. et al. Dispersal modes and fruiting periods in hyperseasonal and seasonal savannas, central Brazil. Revista Brasileira de Botânica, v. 32, n. 1, p. 155-163, 2009. DOI: 10.1590/ S0100-84042009000100015.

Silva Junior, M. C. Árvores do Cerrado: guia de campo. Brasília, DF: Rede de Sementes, 2005. 278 p.

Silva Junior, M. C. \& Pereira, B. A. S. + 100 árvores do Cerrado: matas de galeria: guia de campo. Brasília, DF: Rede de Sementes do Cerrado, 2009.

Silva, J. S. Padrões fenológicos no Distrito Federal: congruência entre dados de herbário e estudos em campo. 2014. 204 f. Tese (Doutorado em Botânica) - Universidade de Brasília, Brasília, DF.

Silvério, D. V. et al. Surface fire drives short-term changes in the vegetative phenology of woody species in a Brazilian savanna. Biota Neotropica, v. 15, n. 3, e20140077, 2015. DOI: 10.1590/1676-0611BN-2014-0077.

Sobral, F. L. \& Cianciaruso, M. V. Estrutura filogenética e funcional de assembléias: (re)montando a ecologia de comunidades em diferentes escalas espaciais. Bioscience Journal, v. 28, n. 4, p. 617-631, 2012.

Souza, B. C. et al. Divergências funcionais e estratégias de resistência à seca entre espécies decíduas e sempre verdes tropicais. Rodriguésia, v. 66, n. 1, p. 21-32, 2015. DOI: 10.1590/2175-7860201566102.

Spera, S. T. et al. Características físicas de um Latossolo VermelhoEscuro, no Cerrado de Planaltina, DF, submetido à ação do fogo. Pesquisa Agropecuária Brasileira, v. 35, n. 9, p. 1817-1824, 2000. DOI: 10.1590/S0100-204X2000000900014.

Stefanello, D. et al. Síndromes de dispersão de sementes em três trechos de vegetação ciliar (nascente, meio e foz) ao longo do rio Pindaíba, MT. Revista Árvore, v. 33, n. 6, p. 1051-1061, 2009. DOI: 10.1590/S0100-67622009000600008.

Tilman, D. Functional diversity. In: LEVIN, S.A. (ed.). Encyclopedia of biodiversity. San Diego: Academic Press, 2001. p. 109-120.

Vale, A. T. \& Elias, P. S. Nível de proteção térmica da casca de quatro espécies lenhosas e a relação da arquitetura da casca com a transferência de calor. Ciência Florestal, v. 24, n. 4, p. 977-985, 2014. DOI: 10.1590/1980-509820142404017.

Vale, A. T. et al. Influência das propriedades da casca de Vochysia thyrsoidea na transferência de calor para o câmbio. Revista Científica Eletrônica de Engenharia Florestal, v. 8, n. 13, 2009.

Vale, V. S. et al. Functional groups in a semideciduous seasonal forest in Southeastern Brazil. Biotemas, v. 26, n. 2, p. 45-58, 2013. DOI: 10.5007/2175-7925.2013v26n2p45. 
Vale, V. S. et al. Grupos funcionais e sua importância ecológica na vegetação arbórea em um remanescente florestal urbano, Uberlândia, MG. Natureza on line, v. 9, n. 2, p. 67-75, 2011.

Valentin, J. L. Ecologia numérica: uma introdução à análise multivariada de dados ecológicos. Rio de Janeiro: Interciência, 2000. 117 p.
Zilli, G.Z. et al. Avaliação temporal das características funcionais de espécies arbóreas em fitofisionomias da transição Cerrado-Amazônia, Mato Grosso, Brasil. Biotemas, v. 27, n. 4, p. 51-61, 2014. DOI: $10.5007 / 2175-7925.2014 \mathrm{v} 27 \mathrm{n} 4 \mathrm{p} 51$. 